cal activity of ozone tends to its dissipation. If, there-
fore, in the long course of ages the quantity of this triatomic form of nitrogen remains inappreciable, we
are scarcely entitled to assume its existence as a normal constituent of the atmosphere, unless we also as
sume that it is being utilized in some unknown was. It is not the first time that chemists and phon allotropic formoted to believe in the progen, and toaceptit as explan of an certain curious phenomena, but hitherto the assump-
tion has always broken down on more careful investi gation. This time we may be permitted to hope that
the elusive allotropic form has been fairly captured.

\section{ON THE CHEMISTRY OF COAL FORMATION.*}

By J. W. THOMAS, F. C.S., F.I.C.

"Writr a view to lead up to the consideration oi the "proximate chemical constituents of the various kind ation, will open the question respecting further experiIt is to be expected that the age of the coal, and the
physical conditions such as the effect of water, heat physical conditions such as the effect of water, heat, the chemistry of coal formation. If the tertiary the upper bituminous coals of the South Wales field, a striking gradation and regularity of change is seen
between the lignite and the anthracite, as shown in the accompanying table. The lignites are soft, anthracite is very hard; lignites are wet, anthracite dry;
lighites show high hygroseopicity, anthracite low. In the table the physical characters run fairly parallel
with the chenical. In East Yorkshire the oolitic coals- jet, for instance-are as hard, and dry, and as little hygroseopic, as anthracite ; and so is the highily
bituminous Wigan cannel. The Scotch coals also furn. ish exceptions to the rule, and the physical conditions
of the coals of Great Britain are of little value in deterof the coals of Great Britain are of little value in deter-
mining their chemical character ; and as there are inmining their chemical character ; and as there are in-
stances of bituminous coals lying below more anthrastances of bituminous coals lying below more anthra-
cite varieties, even the depth of the coal below the surface is no safe criterion of its chemical composition.
The decomposition of peat and wood to-day teaches us nore respecting the chemistry of coal formation
The late Dr. Angus Smith showed that the wood The late Dr. Angus Smith showed that the woody
fiber of recent decaying moss decomposed much quick. fiber of reent decaying moss decomposed much quick.
er than the resinous and gummy portions, the result older peat, and a corresponding loss of combined oxy-

Oebserving the decomposition of wood to-day in the case of larch and pine railway sleepers, we see that
the portions where the resinoids are in least quantity re first attacked, the knots and other parts sturate with resin and terpeenes being preserved after all the
woody fiber has distrppearef.
We know, too, that decomposition is greatly accelerated by myriads of
inseet and lower life, all of which appear to dislike insinous matters. Thus in forest decomposition, as
well as in peat there is an increase of resinous matter well as in peat, there is an increase of resinous matter
due to the rapid dissociation of the woody fiber. I am giving attention to the decomposition of wood, as urther experiments are wanted in this direction. it is found that je tertiary formation of Bovey Tracey decomposition, the lignites have an excess of resinous matter in them: and there is, moreover, a considerable
quantity of resin in lumps unmixed with the lignite coal. This resin melts at a low temperature and the
strata do not show the effect of much heat. Hatchett strata do not show the effect of much heat. Hatchet
named this resin "retinasphaltum," and it was further

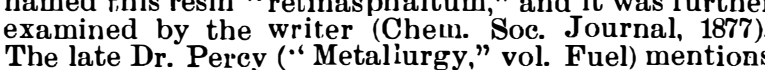
coals, apparently of tertiary origin, froul New Zealand, etc., containing particles of resin. Dr. Hofmann, in Roy. Soc. Canada, 1889), showed that certain coals. chiefly of tertiary orifin, contained grains of mineral
resin disseminated through them. And Mr. Watson resin disseminated through them. And Mr. Watson
Snith (Journ. Soc. Chem. Ind., 1892, 1893) found in the
Miike coal of Japan as much as 9.5 per cent. of bituminous matter. It must be inferred, therefore. nous matters in lignite coals, and it is a curious fact
that the woody varieties, and even the "leafy" coal
of Bovey Tracey, composed of branches and leaves in perfect preservation, contained resinous matters in in the vegetable material in its normal condition. The same is true of those beds of lignite which have all the study of the Bovey Tracey lignites it is not only evident that conifers and other dicotyledonous trees
flourished, yielding much resinous and terpene componds, but that the condition of vegetation was such from some of the trees during the tertiary coal period The yellow resinfound in quantity in the Bovey "Tracev
formation shows that the resinoids in the "leafy" formation shows that the resinoids in the "leafy"
and "wood y" coals are not the result of the melting and soakage of the accumulated resinoid matters. As made up of conifers and dicotyled the Bons, the above conmasions may not be much questioned : but what of
the coals of the carboniferous age ? Where would the showers of liquid gummy and resinous matters come
from when the vegetation was monocotyledonous? from when the vegetation was monocotyledonous
Witham long ago pointed out the mistake which is frequently made to-day, and he showed, sixty years of carboniferous coal, remarking. "I I must contend that there existed coniferemas trees, or such as contend erl a complicated woody structure in great abundance."
More recent search has revealed, chiefly in the strata More recent search has revealed, chiefly in the strata intermediate with the coal beds, many dicotyledons
other than conifers; hence there is no evidence wantcoal of carboniferous age. Mr. Hutton (Lond, and Edin. Phil. Mag., 1833) mentioned that he observed under the microscope that some of the coals of the of a yellow bituminous resinoid, so volatile as to be
easily expelled by heat without altering the structure *A A paper read before the British Association (Section B), Oxford meet
ing,
THE LIGNITES OF BOVEY TRACEY, AND COALS OF THE SOUTH WALES FIELD.

\begin{tabular}{|c|c|c|c|c|c|c|c|c|c|}
\hline \multirow[t]{2}{*}{ Description. } & $\begin{array}{c}\text { Soft } \\
\text { or hard. }\end{array}$ & $\begin{array}{l}\text { Wet } \\
\text { or dry. }\end{array}$ & Bygro- & Carbon. & $\begin{array}{c}\text { Hydro- } \\
\text { gen. }\end{array}$ & Oxygen. & $\begin{array}{l}\text { Nitro- } \\
\text { gen. }\end{array}$ & Sulphur. & Ash \\
\hline & \multirow[b]{2}{*}{$\begin{array}{l}\text { Soft } \\
\text { Medium }\end{array}$} & \multirow[b]{2}{*}{ Wet } & \multirow{2}{*}{\begin{tabular}{|c|} 
Per cent. \\
$\begin{array}{c}15 \cdot 0 \\
10.0\end{array}$
\end{tabular}} & \multicolumn{6}{|c|}{ Per cent. on dry kample. } \\
\hline $\begin{array}{l}\text { Soft lignite } \ldots \ldots \ldots \ldots \ldots \\
\text { Com pact lignite............... } \\
\text { Upper carboniferous с о a }\end{array}$ & & & & $\begin{array}{l}59 \cdot 9 \\
66 \cdot 7\end{array}$ & $\begin{array}{l}6 \cdot 0 \\
5 \cdot 5\end{array}$ & $\begin{array}{l}25 \cdot 0 \\
20 \cdot 0\end{array}$ & $\begin{array}{l}0.6 \\
0.8\end{array}$ & $\begin{array}{l}1.5 \\
2 \cdot 0\end{array}$ & $\begin{array}{l}7 \cdot 0 \\
5 \cdot 0\end{array}$ \\
\hline 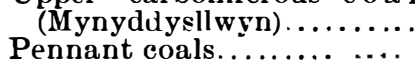 & Hard & Medium & $\begin{array}{l}6 \cdot 0 \\
4 \cdot 0\end{array}$ & $\begin{array}{l}79 \cdot 5 \\
81.5\end{array}$ & $\begin{array}{l}5 \cdot 5 \\
5 \cdot 0\end{array}$ & $\begin{array}{l}4 \cdot 5 \\
4 \cdot 5\end{array}$ & $\begin{array}{l}1 \cdot 5 \\
1.5\end{array}$ & $\begin{array}{l}3 \cdot 5 \\
3 \cdot 0\end{array}$ & $\begin{array}{l}5 \cdot 5 \\
4 \cdot 5\end{array}$ \\
\hline Semi-bituminous coal.... ... & 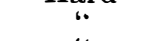 & "“ & $2 \cdot 5$ & $84 \cdot 2$ & $4 \cdot 5$ & $4 \cdot 0$ & $1 \cdot 3$ & 2.0 & $4 \cdot 0$ \\
\hline $\begin{array}{l}\text { Steam coal } \ldots \ldots \ldots \ldots \ldots \\
\text { Anthracite coal. } \ldots \ldots \ldots \ldots\end{array}$ & Very hard & Dry & $\begin{array}{l}1 \cdot 5 \\
0 \cdot 5\end{array}$ & $\begin{array}{l}87.8 \\
91.7\end{array}$ & $\begin{array}{l}4 \cdot 2 \\
3 \cdot 5\end{array}$ & $\begin{array}{l}3 \cdot 0 \\
2 \cdot 5\end{array}$ & $\begin{array}{l}1 \cdot 0 \\
0.8\end{array}$ & $\begin{array}{l}1.0 \\
0.5\end{array}$ & $\begin{array}{l}3 \cdot 0 \\
1 \cdot 0\end{array}$ \\
\hline & 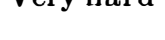 & & & & & & & & \\
\hline
\end{tabular}

of the coal: and, since then, similar observations have These facts show that what was true of the Bovey carboniferous age, and there seems every probahility that not only did conifers and other dicotyledonous
trees flourish during the carboniferous period, but trees fourish during the carboniferous period, but
that much liquid gummy and resinous matters were
showered from the trees upon the dried and decomposing material on the surface. It is well known that arious trees, like the lime, for instance, during the to render its leaves and the grass underneath covered coniferous trees, like the Scotch fir, shower terpenes and resinoid matters upon the ground beneath. It is as having a weighty bearing upon the chemistry of coal formation, not only during the tertiary, but also during the carboniferous age.
It has long been an enigma to botanists and geolgists why the forms of the delicate ferns of the carboniferous coal period should be so perfectly preserved, delicate undergrowth, when dying and drying, became saturated with liquid resinous matters falling from the trees, and, in this way, were preserved from putre
faction, to imprint their beautiful forms upon the hale and rock above the coal, and in other positions. vetation during the carboniferous age, and the denature of coal, as we find it, is the result, not so much of heat and pressure and decomposition in its deeply buried condition, as upon the character of the primary decomposition which took place at or near the surface,
together with the nature of the material from which the coal was formed.

Starting with the bituminons shales, like those used
y the Young Candle Company, and at the Pump hy the Young Candle Company, and at the Pump-
herston Works in Scotland, I believe that there, as herston wown the mineral strata, huge forests flourished
from which the woody fiber was eliminated by surface high percentage of mineral matter favors tlinis view. Th high percentage of mineral matter favors this view.
Resinous vegetation, without much dicotyledons, or with dicotyledonous trees, much surface decomposition, by long continued exposure would produce
Scotch cannel, rich bituminous coals, Wigan cannel, A luxurious resinous and dicotyledonous vegetation. without much surface decomposition, probably gave
rise to semi-bituminous, steam, and anthracite coal, ssisted, of course, by heat and pressure.
Now as to our present knowledge of coal itself.

1. It contains water, and retains some after long exposure in dry air. As shown in the table, the quantity
of water retained by a coal after drying at ordinary the coal-being highest, in lignite and lowest in anthe coal-being highest, in lignite and lowest in an-
thracite. Jet, and numerous coals of the carbonierous age in various coal fields, are exceptions to the
rule. Some lignites contain 30 per cent. of water in the natural condition, but the better qualities do not hold ing to 10 per cent. Such coals as are used for fuel in
this country rarely hold more than 5 per cent after this country rarely hold more than 5 per cent. after
being air dried. Coals which we ship abroad in their air-dried condition generally contain less than 3 per cent. of moisture; while steam and anthracite coal
from dry seams do not hold more than 1 per cent. of moisture. Coals won from seams to which water gains
access contain much larger quantities of water ; but $I$ am referring now to the hygroscopicity of coal

of moisture air-dried coal contains but to call attention of moisture air-dried coal contains, but to call attention
to how this moisture is held. If the water still retained in an air-dried sample of coal be driven off by heat and the dried coal afterward exposed in a moist atmosphere, the moisture is reabsorbed at a very quick
rate and so great is the hygroseopicity of some coals
that it is not possible to estimate the water in an open that it is not possible to estimate the water in an open vessel, as the weighing cannot be done quickly enough
to prevent reassorption. Dr. Hofmann, of the Canadian Geological Survey, has shown that a portion
of the water in coal is most obstinately held, and there is no doubt, I think, that it exists in chemical com-
bination. In the deep dry steam and anthracite coals as they occur in their seams, there is, probably, no point, and in the analyses of coal the hygroscopicity
has not received due attention. Furthermore, it seems to me that the hygroscopicity of coal is the key to the property of spontaneous combustion, and shoul 2. Coal contains the gases, oily matters, and solids of the paraffin series. In my experiments on the gases of the paraffin series, and, in one instance, white solid paraffin from a coal of carboniferous ure. Mr. Watson
Smith's experiments (Journ. Soc. (1) Mrem. Ird., 1893) show conclusively that liquici and solid paraffins exist ready formed in coal, but they rarely exceed 1 per cent.
in Coals of the carboniferous period. 3. Coals contain 0.5 to 10 per cent. of ash or minera
matter in good samples, and from 0.5 to 4 per cent. of
sulphur, generally present as disulphide $\mathrm{FeS}_{2}$, in coals of carboniferous age. In lignites it frequently occur 4. The bulk of coal consists of carbon, hydrogen, and the nitrogen is combined is not known. The same remark applies to the carbon, some of which doubtless is arbon is free and how much is in combination with oxygen is generally regarded as being combined with hydrogen, but I do not think that this is the case with the dry deep coals containing occluded marsh gas; robably the condition.

In conclusion, I suggest that further experiments be 1. Upon the decomposition of dicotyledons with a
Und in the following directions view to throw light upon the formation of cos study it bearing upon the spontaneous combustion of coal on 3. Upon the coals from all the British coal fields to
3 determine the quantity, and, if possible, the consti-
tuents soluble in gasnlene (petroleum ether), or ben tuents soluble in gasnlene (petroleum ether), or ben
zine, as employed by Mr. Wilson Smith. tion of potassic hydrate.

\section{THE PTOMAINES FORMED DURING PUTREFACTION.}

By C. A. Mitchell, B.A. Oxon.

SELDOM does a year pass without the medical jour or fish. It is no uncommon thing to hear of whole
families suffering from the effects of eating mussels, whil to mos and he attack ends in death, as in the case mentioned by Czraut in his "History of Greenland." where thirtytwo persicus died from eating the brains of a walrus which had begun to decompose. In other instances arge quantity of the substance has been eaten. These are now believed to be due to the preselice of one or The name "alkaloids" was formerly confined to the cumstances by the vegetable protoplasm of certain plants, and containing, in addition to nitrogen, varying quantities of carbon and hydrogen, and in some
cases oxygen. They may be solid and crystalline like trychnine, or a volatile liquid like nicotine, the alk:less soluble in water, combine plant. They are more or form salts, and have characteristic test reactions by containing the same elements arranged in a different manner. Many of them act as deadly poisons on the A similar class of substances is formed in living ave been called leucomaines, while the alkaloids formed after death in the course of putrefaction have which the first known were extracted from normal in snall quantities into animals. In composition they are, as a general rule, less complex than the ptomaines, though this distinction cannot be rigidly maintained. ence, and assert that they are not formed in the liv-
ing body, but are ptomaines absorbed from the intesing body, but are ptomaines absorbed from the intesThat poisonous principles could be extracted from decaying meat was known long ago, but our knowldge of them is quite recent. In 1856, Prof. Panum, of Copenhagen, extracted from the flesh of dogs a poisonafterward sepsin. The name ptomain ss ( $\pi \tau$, who applied it to a mixture of alkaloical products which he had separated from the putref ying remains
of dead bodies. It has since become the general term for these products. It used to be thought that these tical chemical composition. $\S$. Brieger, to whom we owe much of our knowledge of
he subject, defines the ptomaines as "all nitrogenou bases formed by the action of bacteria," but it is more during putrefaction. This process, as was shown by
Pasteur in 1863, is a species of fermentation carried on

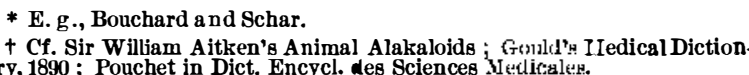
†
†. Spicca, Gazetta, ii., $486-487$. an only be traced to the eating of un wholesome meat tissue by Gautier in 1886, are in many cases non-poi-
sonous, though some which have been prepared from animal alkaloids were different in kind to those formed
in the vegetable kingdom, $\ddagger$ but recent research has proverties, and are in some cases of apparently iden- 
by micro-organisms derived from the air. It is a property of vegetable and animal nitrogenous substances, unless artificial means of preventing it occur, the work "Tore stable forms commences. As Huxley says form are the characters of that portion of the universe would not undergo putrefaction if protected rom air germs, has since been again and again verified by only
allowing access to air which had been sterilized by heating or filtration. Heating on successive days in
steam or by dry heat at a higher temperature will destroy bacteria, or they may be removed by drawing
afr through cotton wool, which will retain them; and Tyndall's experiments also proved that organic matter protected from micro-organisms would not putrefy. In this work of disintegration two classes of organisms
bear part-the aerobic, which require the presenee of oxygen, and the anaerobis, to which that gas is fatal.
After death the body becomes a suitable culture medium for the reception of the anaerobic bacteria (vibriones) with which the air swarms. Some of these falling
on the body draw their nourishment from the albuminous substance, splitting it up into simpler forms, and thus produce putrefaction. Fo complete the work of
destruction the assistance of aerobic organisms is essen tial, for the vibriones, living without oxygen, sooner
or later perish, and are themselves oxidized. Oxidation is the name given to the chemical process in which
substances combine with oxygen. Since about one-tifth of the atmosphere is composed of this gas, the process
is continually going on in nature. Familar examples of it are the rusting of iron and the burning of wood, where the heat enables the carbon and hydrogen in
the wood to enter into combination with the atmospheric oxygen. The aerobic organisms which com:
plete the work belong to the class of moulds, and on their advent the oxidizing process continues until the and stable forms.

The mechanical process of putrefaction was studied horseflesh, which were odorless and having a slight acid reaction, were exposed to the action of putrefactive arganisms. After a time, there was an acid odor, and
cided werum-like fluid exuded. This apparently coincided with the commencement of fermentation. Large
bacilli were present, and the gases given off were ammonia and carbonic acid, with a little sulphureted hyfrogen and phosphureed hydrogen. Toward the given off, and at this point putrefaction proper com-
menced. The large bacteria disappeared, being replaced by very small ones, which attacked the albumimonia, and quickly causing the mass to become
alkaline. The germs producing putrefaction are in themselves
harmless, and the poisons produced during their work harmless, and the poisons produced during their work which they feed or by their secreting some chemical
product. Prof. Burdon Sanderson has shown that when dead matter. such as blood serum, is deprived of
every trace of living organism, it still possesses the
power of producing disease when introduced into the blood of animals.

the ptomaines frome following method for extracting nal organs were placed in a cold cellar for from twentyslightly acid with hydrochloric acid, heated nearly to
boiling, and concentrated by evaporation. Alcohol was added to extract the alkaloid, which was then precipitated by platinic chloride. Alkaloidal bodies are treatment. With this the ptomaine would to a great extent be separated from other animal products. On now adding to the clear filtered liquid a solution of
platinum chloride, which combines with alkaloids, a compound containing the ptomaine, insoluble in the
alcohol, would be formed. This, filtered off, would leave most of the impurities still dissolved in the alcohol. From this combination the ptomaine choline was
proceed further, other ptomaines besides choline were ormed.

Like the vegetable alkaloids, some of the ptomaines
contain no oxycen, while others have four or contain no oxycen, while others have four or six atoms
in the molecole. The term "atom" is a theoretical term to denote the smallest particle of a substancemay be defined as the smallest particle of a substance
capable of separate existence. There are usually two capable of separate existence. There are usually two
or more atoms in a molecule. Mytilotoxine, the alkaloid separa ted by Brieger from
putref ying mussels, may be taken as a typical ptomaine Its percentage composition is :

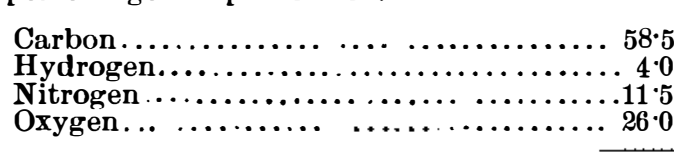

Other well-defined animal alkaloids are neurine,
wich, like choline, is found in putrid flesh, and tyrowhich, like choline, is found in putrid flesh, and tyro-
toxicon, which occurs in nilk, and was the alkaloid Most of them are extremely poisonous, and very
minute injections have proved fatal to birds and small minute injections have proved fatal to birds and smait
animals. The general symptoms are increased activity
of the secretive organs and slowness of the heart's of the secretive organs and slowness of the heart's
action, often followed by convulsions, paralysis, and
death. In some of the cases of poisoning by putrid death. In some of the cases of poisoning by putrid
fish, there has been dilatation of the pupil of the eye be very similar to that of curare. $\$$
Closely allied to the ptomaines in composition are the products formed by the pathogenic bacteria; they cultivations of disease organisms after removal of these organisms by filtration through porous porcelain.

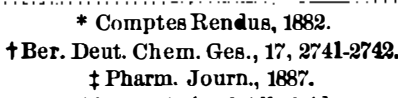
$\ddagger$ Pharm. Journ., 1887.
SAitken, Animal Alkaloid.
Disease organisms are cultivated outside the body by
introducing a fragment of diseased tissue or blood containing the organisms into a tube in which is some medium, such as gelatine, on which the bacteria can
grow. When such a "colony" is obtained, containing cultivation." It is highly probable that these albumoses are the poisons by means of which the bacteria pros produced results in some instances analogous to
those obtained by inoculating with the bacteria themwhich they appear to be connected. Thus we have vation of the diphtheria bacillus, and scarlatinine and puerperaline connected with scarlet and puerperal
evers. Quite recently* Dr. Griffiths stated that he had isolated an albumose which he believed to be connected with influenza. It was a white substance,
crystallizing in needles, soluble in water, and having a
slightly alkaline reaction. Injected, it was extremely poisonous, producing much fever, followed by death poisonous, producing much fever, followed by death
n eight hours. Whether it really is a cause of influenza
equires corroboration, and indeed the whole subject ledge.

CHEMISTRY AT THE BRITISH ASSOCIATION.

THE meeting of section B at Oxford, Nature says, will That portion of the president's address urging upon in their curriculum will doubtless have valiable re
the the course of the meeting may be described as emoch making. The presence of a large number of proceedings nemorable and attractive.

The committee for preparing an international stand ard for the analysis of iron and steel reported that
their work was now completed and that it is proposed to shortly deposit the standards with the Board
of Trade, or with some other suitable authority where they will be at the public service. Prof. Clowes gave carbonic acid in air which are extinctive to flame, and
which are irrespirable. He tinds that the flanies of andles, oil, paraffin and alcohol are extinguished by The containing from 13 to 16 per cent. of carbonic acid.
The flame of coal gas, however, required the presence of at least 33 per cent. of the extinctive gas, and the lame of hydrogen was not extinguished until the
amount of carbonic acid in the air reached 58 per cent.
Comparing his experiments with those of $\mathrm{Mr}$ J. R. Comparing his experim ents with those of Mr J. $R$. Wilson on the percentage of carbonic acid required to
suffocate a rabbit, Prof. Clowes concludes that air containing at least 10 per cent. of carbonic acid more
than is required to extinguish a candle flame can breathed with impunity. By taking advantage of the extraordinary vitality of the hydrogen flame in pres-
ence of high proportions of carbonic acid, it is possible o maintain the flame of the conıposite safety lamp
p.eviously described by the author) after the oil flame p.eviously described by the author) after the oil flame
has been extinguished.
Mr. Haldane concluded from some experiments he has made on the respirability of air containing carbonic acid that the percentage of this gas considered
Much interest was shown in the successful experiMuch interest was shown in the successful experi-
ments of Dr. Lobry de Bruyn, demonstrating the pro. ments of Dr. Lobry de Bruyn, demonstrating the pro-
perties of free hydroxylamine. On heating a small amount in a test tube, a sharpexplosion took place. iodized starch paper to have become converted into nitrous acid. In a series of test tubes its behav-
ior with various reagents was demonstrated. With
potal potassium permanganate and with chromic acid oxibichromate produced an explosion. The anhydrous
sulphates of copper and cobalt were reduced by the substance. Free hydroxylamine was dissolved in
anhydrous ether and sodium added, hydrogen was anhydrous ether and sodium added, hydrogen was
evolved and the very explosive sodium compound
of hydroxvlamine produced. Chlorine and iodine were shown to act spontaneously on hydroxylamine, producing inflammation. It is of interest that hydroxylamine
will dissolve many salts which are soluble in water, the order of solubility differing in the two solvents.
Dr. Bernthstein described a new bacterium

Dr. Bernthstein described a new bacterium which
occurs in milk, whose chief property is that of peptonizing the caseine, thus forming a soluble compound,
and rendering the milk transparent, and more readily digested.

A discussion took place on the behavior of gases
with regard to their electrification, and the influence of moisture on their combination. It was opened by perimentsillustrating the connection between chemical change and electrical discharge through gases. The
gases were confined, under a pressure of about $100 \mathrm{~mm}$., in glass bulbs which were placed in the center of a coil
of wire connecting the exterior of two Leyden jars, of wire connecting the exterior of two Leyden jars,
the interior coatings of which were connected with the two poles of a Wimshurst machine. As each spark alternating current is set up in the coil, and hence by
induction in the gas. In the case of oxygen it was found that the moist gas gives a vivid incandescence,
followed by an afterglow or phosphorescence, on followed by an afterglow or phosphorescence, on re-
moving the bulb from the coil. With the dry gas, on the other hand, incandescence does not take place.
The incandescence can, however, be started in the dry gas by a brush discharge, and if once started, conWith air the phenomenon is reversed; damp air does
not glow dry air will. By making use of two coils in not glow, dry air will. By making use of two coils in
one of which was a beaker of fairly strong sulphuric acid. and in the other a bulb containing moist oxygen, the presence of the acid was shown to prevent the in-
candescence in the bulb, showing the conductivity of the gas to be much greater than that of the acid. As
the glow is only given in gases forming polymeric modifications, it is suggested by Prof. Thomson that the he original molecules to dissociate. In the case of

*Chemical News, Nov. $\pi 7,1893$ dry gases this preliminary dissociation can only be energy. Alcohol vaturor will behave similarly to water Mr. Brereton Baker followed with some experiments
B. He showed that ammonia and hydrochloric acid when dry do not combine. He also exhibited tubes containing dry sulphur trioxide and cupric oxide, and dry sul-
phur trioxide and lime. side by side, without action upon one another, a kind of "chemical happy family." moisture is physical rather than chemical, from the fact arbon and oxygen, no action takes place. He has sing semi-vacuous tubes, into one end of each of which a platinum wire is fused and which contain a small quantity of mercury. On shaking these tubes in dark room incandescence takes place in those con-
taining moist oxygen. This is less if nitrogen is pres-
ent, and ceases if the gas is dry. - Dr. Ewan read a ent, and ceases if the gas is dry. - Dr. Ewan read a
patper on the rate of oxidation of phosphorus, sulphur
and aldehyde. The results obtained with aldehyde are free from the uncertainty produced by the correction
for the changing rate of evaporation. When proper precautions are taken, this reaction goes perfectly
regularly at $20^{\circ}$, and its velocity is proportional to square root of the pressure of the oxygen. These results are most simply explained by assuming (in accordance with Williamson's theory) that the oxygen
frst splits up to some small extent into atoms, and that these alone take part in the oxidation.
Prof. Hartley described some new methods of specProf. Hartley described some new methods of spec-
rum analysis and some Bessemer flame spectra. He
has found that if a mixture containing alkalies and alkaline earths be fused with borax or silica, the alkalies are first volatilized and give their characteristic high temperatures it has been found useful to heat the substance in the oxyhydrogen flame on a rod of
kainite, pipe clay, or dried alumina. The elements can be clissified according to the type of spectrum given
under these conditions. On vaporizing alloys, those under these conditions. On vaporizing alloys, those ound to produce line spectra. e. g. silver, in an alloy
of copper and silver. This is thought to be due to the when alloyed and when in the free state. when alloyed and when in the free state.
A large audience assembled to hear the announcement by Lord Rayleigh and Prof. Ramsay of the existcertain experiments of Cavendish pointed to the presence, in air, of some substance other than the gases
with which we are familiar. Attention was recalled to his substance by the fact that the density of nitrogen obtained from atmospheric air differs by about 1/2 per ources. It was found that if air (withexcess of oxygen) umes absorbed by potash, and the excess of oxygen by alkaline pyrogallate, their remains a residue which spectrum. The same gas can be isolated by exposing
nitrogen obtained from air to the action of magnesium. As the magnesium gradually absorbs the nitrogen, the As the magnesium gradually absorbs the nitrogen, the The newly discovered substance constitutes nearly per
cent. of the atmosphere, and gives a spectrum with a
ingle blue line much more intense than a correspondng blue line in the nitrogen spectrum.

Sir $\mathbf{H}$. E. Roscoe, in proposing a vote of congratula-
ion on the discovery, spoke of the special interest thely Prof. Emerson Reynolds noted the place which the new substance, if it proved to be an element, would
occupy in Mendeleef's table among the platinum Prof. Roberts-Austen suggested that this gas might mong the gases extracted from steel. The president, in putting the vote of congratulation
o the meecing, drew attention to an observation made by Prof. Dewar, that while a mixture of pure liquefied xygen and nitrogen forms a clem liquid, air in a simi-
ar state shows a turbidity. The president suggested b at this turbidity night be due to the new gas.
some very interesting experiments on the electrolysis Some very interesting experiments on the electrolysis
of glass were described by Prof. Roberts Austen. In conjunction with Mr. Stansfield he has found that if a immersed in a vessel of mercury heated in a sand bath to rather over $200^{\circ}$, on connecting the sodium amalgam and the mercury respectively with the terminals of a
battery, sodium will pass from the amalgam through the glass is unchanged. If lithium amalgam be substituted or the sodium amalgam. however, a certain percentage of lithium is found in the glass at the end of the ex.
periment, sodium from the glass is driven into the ercury, and the glass is altered in appearance and frangibility. With potassium amalgam and soda-glass by Prof. Roberts-Austen to depend on the relative atomic weights and conseguent atomic volumes of the
elements concerned. Lithium, having a smaller atomic volume than sodium, is able to follow in the galleries
eft by the atoms of the latter metal; potassium, on the other hand, having an a tomic volume greater than old and copper and different kinds of glass, Prof. Roberts.Austen hopes to throw light on the formation of mineral veins in

REFINING OF CARBON BISULPHIDE. By J. FARBAKY.

RAW carbon bisulphide is contaminated with from 6 to 10 per cent. of dissolved sulphur, and in consecolor and a penetrating od or. The redistillation in orderto purify the chemical has since 1888 been per-
formed successfully by a continuous process. For this formed successfully by a continuous process. For this
purpose an iron vessel is used having a circular cross
section and provided with a wooden jacket. It is 185 